\title{
A Hierarchical Hybrid Method for Screening lonic Liquid Solvents for Extractions Exemplified by the Extractive Desulfurization Process
}

\author{
Daili Peng, Anne-Jan Kleiweg, Jozef G. M. Winkelman, Zhen Song,* and Francesco Picchioni*
}

Cite This: ACS Sustainable Chem. Eng. 2021, 9, 2705-2716

Read Online

ABSTRACT: A hierarchical hybrid method combining experimental-database-derived estimation of extraction performance, quantitative structure-property relationship (QSPR)-based assessment of IL physical and environmental properties, liquid-liquid extraction (LLE) measurement, and process evaluation is proposed to screen practically suitable ionic liquid (IL) solvents for different extractions. From the literature, 47424 infinite dilution activity coefficient (IDAC) data including 12 IL families (e.g., imidazolium, pyridinium, ammonium, etc.) and 13 organic families
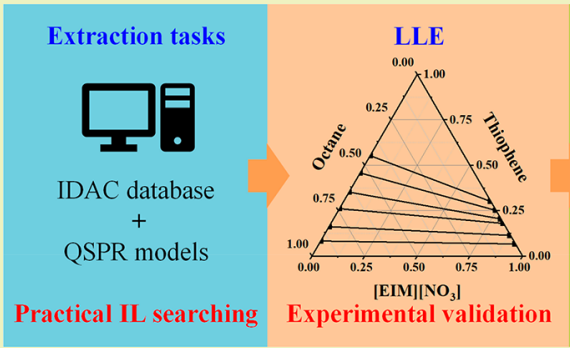
Aspen Plus (e.g., alkanes, aromatics, alcohols, etc.) are collected. On the basis of the IDAC data, the extraction performance of ILs for a specific separation can be estimated in terms of the distribution ratio and selectivity at infinite dilution. The ILs with potentially high extraction performance and meeting the physical and environmental properties criteria are selected to perform LLE experiments. Subsequently, process simulation and evaluation using the selected IL solvents are performed by Aspen Plus. To exemplify the proposed method, the extractive desulfurization (EDS) process is taken as a case study, where $[\mathrm{EMIM}]\left[\mathrm{MESO}_{3}\right]$ (1-ethyl-3-methylimidazolium methanesulfonate) and $\left[\mathrm{EIM}^{-}\left[\mathrm{NO}_{3}\right]\right.$ (1-ethylimidazolium nitrate) are selected after IDAC database searching and QSPR analysis. Experimental LLE with the two ILs are determined, demonstrating their promising extraction performance with the maximum selectivity $\left(S_{23}^{\max }\right)$ for thiophene/heptane of 420 and 281.9 , respectively. By fitting the NRTL model correspondingly, two processes using the screened ILs and sulfolane are developed and compared using Aspen Plus. It turns out that the two ILs save $66 \%$ and $48 \%$ in solvent requirements and 54\% and 55\% in energy consumption compared to those of sulfolane for the EDS task, respectively.

KEYWORDS: Hierarchical ionic liquids screening, IDAC database, QSPR, Liquid-liquid extraction experiment, Process simulation and evaluation, Extractive desulfurization

\section{INTRODUCTION}

Due to their favorable thermophysical properties, ionic liquids (ILs) are widely regarded as promising solvents in various separation processes, such as gas capture, ${ }^{1-5}$ extraction, ${ }^{6-8}$ and extractive distillation. ${ }^{9,10}$ Especially in the extraction process, ILs have been applied in many different areas, e.g., separation of aromatic and aliphatic hydrocarbons, ${ }^{11-13}$ purification of drugs and biomolecules, ${ }^{14,15}$ and desulfurization and denitrogenation of fuel oils. ${ }^{16-19}$ Compared to traditional organic solvents, IL solvents have a negligible vapor pressure that makes them unlikely to evaporate to the environment to cause pollution and solvent loss as well as ease solvent regeneration. ${ }^{20}$ However, there are approximately $10^{18}$ anion-cation combinations that could be potentially synthesized, ${ }^{21}$ making the selection of a suitable IL solvent very difficult. To avoid the labor-intensive liquid-liquid equilibrium (LLE) experiments for the extraction process, the extraction distribution coefficient (eq 1) and selectivity (eq 2) at the infinite dilution condition are usually employed as the preliminary performance measure of ILs: ${ }^{22-27}$

$$
\begin{aligned}
& \beta_{1}^{\infty}=\frac{1}{\gamma_{1}^{\infty}} \\
& S_{12}^{\infty}=\frac{\gamma_{2}^{\infty}}{\gamma_{1}^{\infty}}
\end{aligned}
$$

where $\gamma_{1}^{\infty}$ and $\gamma_{2}^{\infty}$ represent the infinite dilution activity coefficients of solute 1 and solute 2 in IL, respectively; $\beta_{1}^{\infty}$ stands for the solute distribution coefficient of solute 1 , and $S_{12}^{\infty}$ denotes the extractive selectivity.

To acquire the infinite dilution activity coefficients (IDAC) for the solutes in ILs, various methods can be adopted. The classical activity coefficient models, such as the universal functional activity coefficient (UNIFAC), ${ }^{28,29}$ nonrandom two-

Received: October 27, 2020

Revised: January 8, 2021

Published: February 8, 2021 
liquid model (NRTL), ${ }^{30}$ and models from statistical associating fluid theory such as perturbed-chain statistical associating fluid theory (PC-SAFT), ${ }^{31}$ are often used to predict the IDAC. However, to enable accurate predictions, these models need several parameters from the regression of experimental data. This means that the application domain is essentially confined by the availability of experimental data. In contrast, as a theoretical approach combining principles of quantum chemistry and molecular thermodynamics, the conductor-like screening model (COSMO) based methods, namely, COSMO-RS ${ }^{32}$ and COSMO-SAC, ${ }^{33}$ have been demonstrated to be powerful tools for a priori selection of IL solvents in various separation problems. However, for the ILinvolved systems, the accuracy of the COSMO-based models for the prediction of IDAC is inferior to other models such as UNIFAC due to its fully predictive character. ${ }^{34}$ It is worth mentioning that quantum chemistry (QC) and molecular dynamics (MD) simulations have also been widely applied to shed fundamental molecular insights into the extraction mechanism using ILs. ${ }^{35-37}$ However, such methods need intensive computational efforts and are thus not suitable for searching solvents in a large candidate space.

Another avenue to acquire IDAC values is by experiment. Since ILs have negligible vapor pressure, the IDAC of solutes can be measured using the gas-liquid chromatography (GLC) method developed by Everett ${ }^{38}$ and Cruickshank et al. ${ }^{39}$ This experiment usually takes several or dozens of minutes (depending on the retention time of the solutes) to acquire an IDAC data point, and always consumes a few millimoles of ILs. ${ }^{40}$ Although the experimental method is more laborious than the predictive methods (UNIFAC and COSMO-RS can generally output an IDAC within one second depending on the model accessibility), the results are doubtless the most trustworthy. For instance, Song et al. ${ }^{29}$ performed a large extension of the UNIFAC model to IL-solute systems and found that the average absolute relative deviation (AARD) between experimental and UNIFAC calculated IDAC ranges from $8.55 \%$ for " $-\mathrm{COOH}$ " solutes to $37.88 \%$ for " $-(\mathrm{C})_{3} \mathrm{~N}$ " solutes; Paduszyński ${ }^{41}$ reported a comprehensive evaluation of the COSMO-RS in predicting the IDAC for an IL-solute system, concluding that the AARD ranges from $34.5 \%$ for cycloalkanes to $122 \%$ for alkanes, and the overall AARD is $58.5 \%$ for 41868 IDAC data points. Compared to the ILs screened from theoretical databases (e.g., COSMO-RS database) that may be hard to buy or synthesize, the ILs that have been involved in IDAC studies are more practical and easily obtainable. In recent years, a huge amount of IDAC data between various organic solutes and ILs has been reported in the literature, covering typical IL families such as imidazolium, pyrrolidinium, pyridinium, piperidinium, morpholinium, quinolinium, ammonium, phosphonium, sulfonium, etc. That is to say, the IDAC database from the literature could already provide a considerable space to screen practical IL solvents for extraction tasks.

In addition to the extraction performance measure from IDAC, pure-component properties of ILs such as melting point and viscosity are also very important to the extraction process. ${ }^{42}$ A suitable IL solvent should possess a low melting point and viscosity to facilitate the practical application. In addition, the potential hazards of ILs for the environment and human beings are being gradually recognized; ${ }^{43}$ however, this characteristic was rarely considered in previous IL screening or design studies. $^{18,44-46}$ To find environmentally friendly ILs, an estimation of the potential toxicity of them is also of high value.

Once suitable ILs are selected after preliminarily assessing the IDAC and pure-component properties, it is necessary to perform corresponding LLE experiments to validate their performance under practical extraction conditions. However, most available IL screening and design works based on IDAC have neglected the experimental validation. Meanwhile, the experimental LLE data can also be used to accurately regress thermodynamic models such as NRTL, which subsequently allows for reliable process simulation and evaluation. In previous studies that have involved the process evaluation of IL performances for solvent screening or design, the common practice is to directly use the UNIFAC or COSMO-SAC models as the thermodynamic method in process simulation. Despite the convenience of this approach, the process evaluation results may deviate greatly from the real situation due to high sensitivity to the thermodynamic model accuracy. In this sense, thermodynamic models specifically regressed from experimental LLE data could essentially overcome this problem. $^{18}$

In this work, as shown in Figure 1, a hybrid IL screening method that combines the extraction performance estimation,

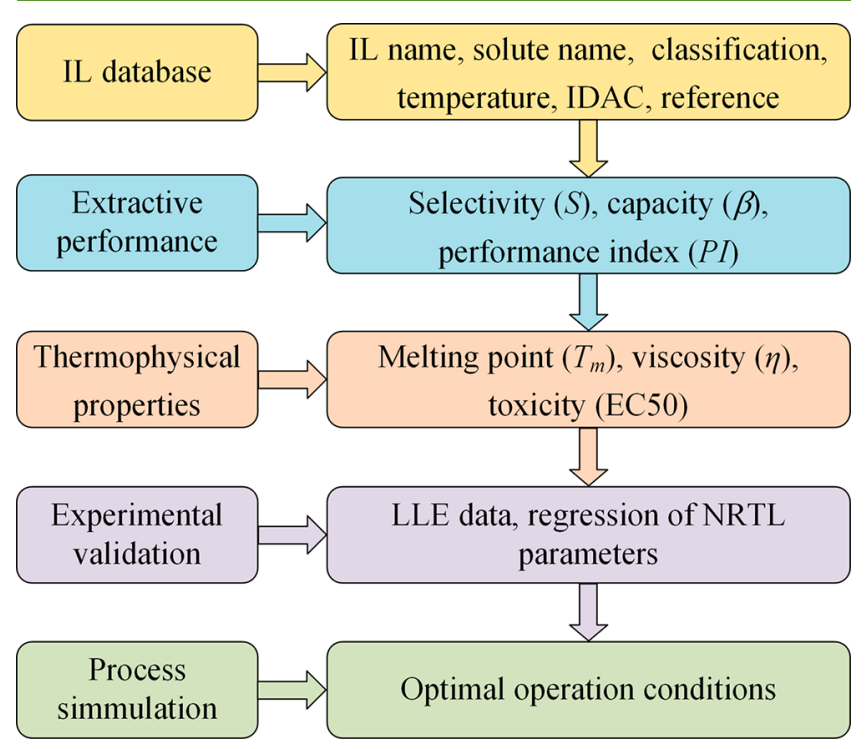

Figure 1. Hybrid IL screening method proposed in this work.

physical property estimation, LLE experimental validation, and process evaluation is developed. In the beginning, a database covering the information on IL and solute name, classification, IDAC, temperature, and corresponding references is built. Then, promising ILs are searched in the database based on the IDAC-derived performance measure. Afterward, the physical properties, namely, melting point, viscosity, and toxicity of the IL candidates, are evaluated using either experimental data or semiempirical models. ILs with both potentially good extraction performance and favorable physical properties are chosen to perform the LLE experiments. Finally, based on the NRTL model regressed from the LLE data, the continuous extraction process using the selected IL solvents is built and compared with the benchmark process using conventional solvents. To demonstrate the method, the extractive desulfurization (EDS) of fuel oils, one of the most extensively 


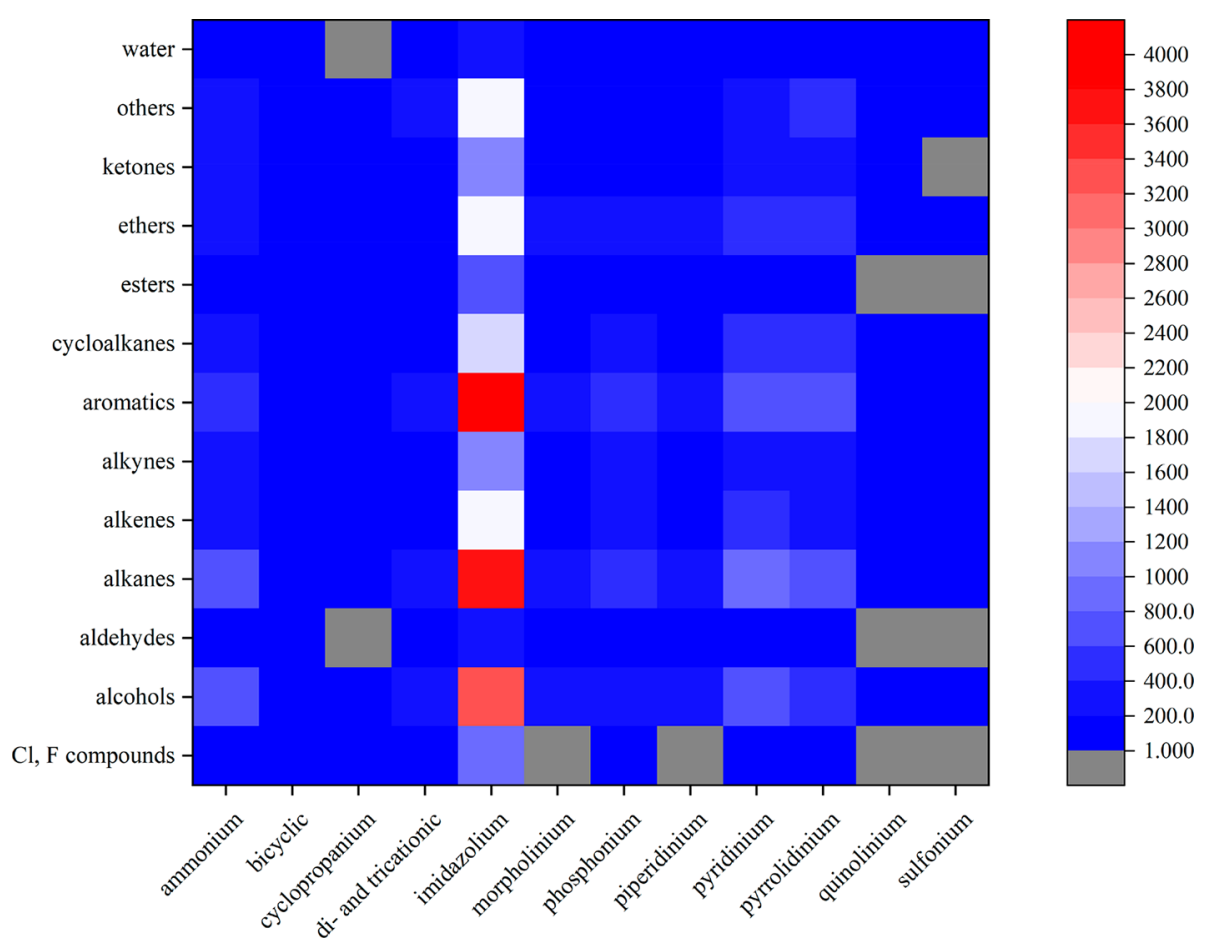

Figure 2. Number of data points among organic solutes and ILs in the database.

studied IL-based extractions in the literature, is taken as a case study.

\section{METHOD DETAILS}

IDAC Database Collection. The database covering 47424 IDAC data points, and the detailed information including the name of the IL and solute, classification, IDAC value, temperature, and references are compiled in Table S2 of the Supporting Information. The combinations of involved organic solutes and ILs as well as the number of data points are shown in Figure 2. As only 11 out of 156 combinations are unavailable in the database, it can be used for screening ILs for many typical extraction tasks such as alcohols/alkanes, aromatics/ cycloalkanes, desulfurization of fuel oils, and so on. The imidazolium family is the most extensively studied since it accounts for a large portion of the data points while other IL families have a quite even distribution. It is worth noticing that the database can be easily expanded in the future when more IDAC data are available.

Searching for Suitable ILs. Because the distribution coefficient is always inversely related to the selectivity, the overall performance of solvents could be evaluated by the performance index $\left(\mathrm{PI}^{\infty}\right)$, which is the product of the selectivity and the distribution coefficient at infinite dilution (eq 3). $\mathrm{PI}^{\infty}$ has been used in many IL screening problems and proved to be a suitable, balanced performance measure. $^{20,26,47-49}$

$$
\mathrm{PI}^{\infty}=\beta_{1}^{\infty} \times S_{12}^{\infty}
$$

To identify the optimal IL solvents for a specific separation problem from the large database, a program in Matlab $(\mathrm{R} 2019 \mathrm{~b})$ is developed to sort the $\mathrm{PI}^{\infty}$ of ILs in the IDAC database for a given separation task. Because many experiments are not performed at exactly the same temperature, the tolerance for the temperature is set to $\pm 1 \mathrm{~K}$.
In addition to the thermodynamic performance measure, the desired IL solvents should possess a melting point lower than the operation temperature and possess a relatively low viscosity (e.g., < $150 \mathrm{cP}$ ). Moreover, the half-maximal effective concentration (EC50) of the biological end points of the Leukemia Rat Cell Line (IPC-81), which is frequently considered in cytotoxicity assessments, ${ }^{50-52}$ is employed to estimate the toxicity of ILs in this work. In order to predict the EC50 value of ILs, a quantitative structure-property relationship (QSPR) model $^{53}$ is used, which is derived from the group contribution based COSMO (GC-COSMO) and the multilayer perceptron technique (MLP). On the basis of the $\sigma$ profile calculated by the GC-COSMO method, the EC50 value of ILs can be predicted by the MLP model. According to the UFT research center (center for environmental research and sustainable technology), $\log$ EC50 $<2$ means the ILs have high toxicity, hence the constraint for toxicity is set as log EC50 > 2. It should be noted that in order to ensure the accuracy of these properties, the experimental data are used whenever possible; otherwise, the QSPR methods ${ }^{53-55}$ from the literature are applied.

LLE Experiments and NRTL Correlation. A mixture containing 5 wt $\%$ thiophene, 45 wt \% heptane/octane, and 50 wt $\% \mathrm{IL}$ is weighted and added to a $10 \mathrm{~mL}$ round-bottom flask with a cap covered in parafilm to avoid chemical loss. The measurements are performed in grams, and the total composition is set to $4 \mathrm{~g}$ using an analytical balance (Mettler AE200) with the readability of $\pm 0.0001 \mathrm{~g}$. The same procedure is carried for higher concentrations of thiophene (i.e., 10, 15, 20,25 , and $30 \mathrm{wt} \%$ ) in the feed while keeping $50 \mathrm{wt} \%$ of the ionic liquid. To ensure complete mixing, the samples are put in an incubator shaker and shaken for $6 \mathrm{~h}$ at 200 strokes per minute. For reaching thermodynamic equilibrium at $298.15 \mathrm{~K}$, the vials are left to settle overnight under isothermal conditions in a water bath equipped with Julabo F25-ED refrigerated and heating circulator, which has a stability of $\pm 0.03 \mathrm{~K}$. 
Samples are carefully withdrawn with syringes from the hydrocarbon-rich layer and IL-rich layer and then determined by gas chromatography (GC) and nuclear magnetic resonance (NMR), respectively. The samples from the hydrocarbon-rich layer are first confirmed to be free of ILs by H NMR analysis using Varian Mercury Plus 400. The GC equipment used is the Agilent Technologies $7890 \mathrm{~B}$ with a flame ionization detector (FID) and an Agilent Technologies DB-5 (15 $\mathrm{m} \times 0.32 \mathrm{~mm} \times$ $0.25 \mu \mathrm{m})$. The IL-rich layer could not be subjected to GC analysis due to the negligible vapor pressure, therefore, the samples are prepared by dissolving a drop in $\pm 0.7 \mathrm{~mL}$ of deuterated methanol placed inside an NMR tube and analyzed by a Varian Mercury Plus 300 or Bruker Avance 600 spectrometer. The average uncertainty in the mole fraction of the GC and H NMR analysis is estimated to be \pm 0.003 . The detailed description of the analysis procedures can be found elsewhere. $^{26,56}$

The Hand ${ }^{57}$ and Othmer-Tobias ${ }^{58}$ correlations are employed to check the consistency of the experimental results

$$
\begin{aligned}
& \ln \left(\frac{x_{2}^{R}}{x_{3}^{R}}\right)=a+b \ln \left(\frac{x_{2}^{E}}{x_{1}^{E}}\right) \\
& \ln \left(\frac{1-w_{3}^{\mathrm{R}}}{w_{3}^{\mathrm{R}}}\right)=c+d \ln \left(\frac{1-w_{1}^{\mathrm{E}}}{w_{1}^{\mathrm{E}}}\right)
\end{aligned}
$$

where $x_{1}, x_{2}$, and $x_{3}$ stand for the molar concentrations of IL, thiophene, and hydrocarbon, respectively. $w_{1}$ and $w_{3}$ represent the weight concentrations of IL and hydrocarbon, respectively. The superscripts $\mathrm{E}$ and $\mathrm{R}$ represent the extract and raffinate phase, respectively. The parameters $a, b, c$, and $d$ are fitted using the experimental data, and the linearity of the results (i.e., the value of $R^{2}$ close to 1 ) indicates the consistency of the ternary liquid-liquid extraction tie lines.

The NRTL model ${ }^{59}$ is used to correlate the experimental LLE data, where the nonrandomness parameters $\alpha_{i j}$ are all set to 0.2 . The binary interaction parameter $\Delta g_{i j}$ is regressed by minimizing eq 6 , and the fitting accuracy is estimated by rootmean-square deviation (RMSD):

$$
\begin{aligned}
& \mathrm{OF}=\sum_{m}^{6} \sum_{n}^{2} \sum_{k}^{3}\left(x_{m n k}^{\exp }-x_{m n k}^{\mathrm{cal}}\right)^{2} \\
& \mathrm{RMSD}=\sqrt{\frac{\sum_{m}^{6} \sum_{n}^{2} \sum_{k}^{3}\left(x_{m n k}^{\exp }-x_{m n k}^{\mathrm{cal}}\right)^{2}}{N}}
\end{aligned}
$$

where $x^{\exp }$ and $x^{\text {cal }}$ denote the experimental and calculated mole fractions, respectively; the subscripts $m, n$, and $k$ represent the tie-line, phase, and component, respectively; $N$ is the number of data points.

Process Simulation. From the practical point of view, it is highly desirable that the optimal solvent for an extraction process is consequently finally identified based on the highest performance in a continuous process. As discussed earlier, ${ }^{20}$ the process simulation based on IL solvents is challenging because of two reasons: (1) ILs are not included in the component databanks of a commercial chemical process simulator (e.g., Aspen Plus); (2) the parameters of the thermophysical models are not available for the IL-involved systems.

In this work, Aspen Plus V11 is used to simulate the extraction process using IL solvents, and the first problem can be solved by defining ILs as pseudocomponents. To address the second problem, the NRTL model is regressed from the experimental LLE data and introduced into Aspen Plus as the thermodynamic method. Moreover, the parameters of the built-in models in Aspen Plus for physical properties are regressed using experimental data or estimated value by the methods listed in Table 1 . This component definition

Table 1. Prediction Models for Physical Properties of ILs

$\begin{array}{lccc}\text { physical property } & \text { data points } & \text { AARD }(\%) & \text { ref } \\ \text { toxicity } & 127 & 4.50 & 53 \\ \text { viscosity } & 1974 & 30.2 & 60 \\ \text { density } & 1999 & 0.90 & 61 \\ \text { heat capacity } & 128 & 5.80 & 62 \\ \text { surface tension } & 162 & 1.17 & 63 \\ \text { thermal conductivity } & 55 & 1.70 & 64 \\ \text { critical properties } & 1130 & & 65\end{array}$

approach has been proved to be reliable for the simulation of IL-containing processes of aromatic/aliphatic hydrocarbons extraction, ${ }^{6,67}$ thiophene/benzene extractive distillation, ${ }^{68}$ and $\mathrm{CO}_{2}$ absorption. ${ }^{69}$

\section{RESULTS AND DISCUSSION}

ILs Screening. The proposed method is demonstrated with the case study of the EDS process at $298.15 \mathrm{~K}$, where \{thiophene + heptane or octane $\}$ is taken as model fuel oils.

On the basis of the screening method introduced above, the ILs in the IDAC database are sorted according to their $\mathrm{PI}^{\infty}$. However, due to the insufficient number of experimental IDAC data at $298.15 \mathrm{~K}$, the screening results under $318 \mathrm{~K}$ are taken into account instead. Accordingly, 67 ILs are picked out from the IDAC database, and their corresponding results for thiophene/heptane and thiophene/octane systems are listed in Tables S3 and S4 (Supporting Information), respectively. For the thiophene/heptane system, $[\mathrm{EMIM}]\left[\mathrm{NO}_{3}\right]$ (1-ethylimidazolium nitrate) and [EMIM] $\left[\mathrm{MESO}_{3}\right]$ (1-ethyl-3-methylimidazolium methanesulfonate) are the top two candidates with $\mathrm{PI}^{\infty}$ values of 240.2 and 153.1 , respectively. For the thiophene/ octane system, $[\mathrm{EMIM}]\left[\mathrm{NO}_{3}\right]$ is still the best with a $\mathrm{PI}^{\infty}$ of 331.8, and [EMIM] $\left[\mathrm{MESO}_{3}\right]$ also has a high $\mathrm{PI}^{\infty}$ (137.4) on the list. Therefore, $[\mathrm{EMIM}]\left[\mathrm{NO}_{3}\right]$ and $[\mathrm{EMIM}]\left[\mathrm{MESO}_{3}\right]$ are first selected as promising IL candidates from the IDAC database.

In terms of pure-component physical properties, the melting point of $[\mathrm{EMIM}]\left[\mathrm{MESO}_{3}\right]$ is below $298.15 \mathrm{~K}^{70}$ while that of [EMIM] $\left[\mathrm{NO}_{3}\right]$ is higher than $298.15 \mathrm{~K}^{71}$ Considering its high $\mathrm{PI}^{\infty},[\mathrm{EIM}]\left[\mathrm{NO}_{3}\right]$ with a melting point below $298.15 \mathrm{~K}^{72}$ is taken as a reasonable substitute of $[\mathrm{EMIM}]\left[\mathrm{NO}_{3}\right]$. The structure of the selected ILs [EMIM] $\left[\mathrm{MESO}_{3}\right]$ and [EIM]$\left[\mathrm{NO}_{3}\right]$ are shown in Figure 3 with their physical properties listed in Table 2. Both the two ILs also meet the criteria of a viscosity below $150 \mathrm{cP}$ and log EC50 larger than 2 . As a protic IL (PIL), [EIM] $\left[\mathrm{NO}_{3}\right]$ has a lower viscosity and toxicity; moreover it is easier to synthesize and purify and hence also has a lower price. $^{73}$ It should be noted that, for [EMIM]$\left[\mathrm{MESO}_{3}\right]$, the viscosity, density, heat capacity, surface tension, and thermal conductivity are experimental values, ${ }^{74-77}$ while other properties in Table 2 are estimated by the methods listed in Table 1.

Experimental Validation. [EMIM] $\left[\mathrm{MESO}_{3}\right](\geq 98 \%)$ and $[\mathrm{EIM}]\left[\mathrm{NO}_{3}\right](\geq 98 \%)$ are purchased from IoLiTec. 
(a)<smiles>CCC1C=C[N+](C)=C1</smiles><smiles>CS(=O)(=O)[O-]</smiles>

(b)<smiles>CCC1C=CNC1</smiles>

Figure 3. Structure of (a) $[\mathrm{EMIM}]\left[\mathrm{MESO}_{3}\right]$ and (b) $[\mathrm{EIM}]\left[\mathrm{NO}_{3}\right]$.

Table 2. Physical Properties of $[\mathrm{EMIM}]\left[\mathrm{MESO}_{3}\right]$ and $[\mathrm{EIM}]\left[\mathrm{NO}_{3}\right]$

\begin{tabular}{lrr}
\multicolumn{1}{c}{ physical properties } & [EMIM] $\left[\mathrm{MESO}_{3}\right]$ & {$[\mathrm{EIM}]\left[\mathrm{NO}_{3}\right]$} \\
viscosity $/ \mathrm{cP}$ & $135.00^{a}$ & 116.00 \\
density $/ \mathrm{kg} \mathrm{m}^{-3}$ & $1242.60^{a}$ & 1221.28 \\
heat capacity $/ \mathrm{J} \mathrm{mol}^{-1} \mathrm{~K}^{-1}$ & $336.41^{a}$ & 248.73 \\
surface tension $/ \mathrm{N} \mathrm{m}^{-1}$ & $0.05^{a}$ & 0.05 \\
thermal conductivity $/ \mathrm{W} \mathrm{m}^{-1} \mathrm{~K}^{-1}$ & $0.21^{a}$ & 0.18 \\
$T_{\mathrm{b}} / \mathrm{K}$ & 667.38 & 610.18 \\
$\mathrm{MW} / \mathrm{g} \mathrm{mol}^{-1}$ & 206.27 & 159.15 \\
$\omega$ & 0.33 & 0.60 \\
$\mathrm{Tc} / \mathrm{K}$ & 1026.03 & 871.46 \\
Pc/bar & 48.13 & 39.95 \\
Zc & 0.33 & 0.26 \\
Vc/cc mol & \\
toxicity/logEC50 & 587.06 & 467.31 \\
${ }^{a}$ Experimental values. & 4.08 & 4.34 \\
\end{tabular}

Heptane $(\geq 99 \%)$ and octane $(\geq 99 \%)$ are purchased from BoomLab and Merck KGaA, respectively, and thiophene $(\geq 99 \%)$ is purchased from Sigma-Aldrich. The ILs are dried for $72 \mathrm{~h}$ at $T=378 \mathrm{~K}$ under a vacuum to remove volatile impurities and trace amounts of water. The LLE results for the ternary systems of $\{$ ILs + thiophene + alkanes $\}$ at $298.15 \mathrm{~K}$ are displayed in Figure 4 and tabulated in Table S5 (Supporting Information). The molar-based distribution coefficient $(\beta)$ and the solvent selectivity $(S)$ are used to assess the performance of the IL solvents for the liquid-liquid extraction process:

$$
\begin{aligned}
& \beta_{2}=\frac{x_{2}^{\mathrm{E}}}{x_{2}^{\mathrm{R}}} \\
& S_{23}=\left(\frac{x_{2}^{\mathrm{E}}}{x_{2}^{\mathrm{R}}}\right) /\left(\frac{x_{3}^{\mathrm{E}}}{x_{3}^{\mathrm{R}}}\right)
\end{aligned}
$$

where $x_{2}$ and $x_{3}$ are the concentrations of thiophene and hydrocarbon, respectively.

For all cases, no ionic liquids are found in the raffinate, which is strongly favorable for the EDS process to avoid the potential contamination of fuel by the nitrogen- and/or sulfurcontaining ILs. ${ }^{78,79}$ Moreover, the concentrations of alkanes in all the extract phase are at a magnitude of $10^{-3}$, which correspond to the high extraction selectivity of the ILs. The results for the Hand and Othmer-Tobias consistency tests are listed in Table S6 (Supporting Information). It can be seen that the $R^{2}$ values for all correlations are close to 1 , indicating the reliability and consistency of experimental LLE data for all the studied systems.

Table S7 (Supporting Information) lists the NRTL regression results, and the RMSDs for the four systems are $0.0067,0.0104,0.0076$, and 0.0071 , respectively. Such low
RMSDs demonstrate an excellent correlation of the NRTL model to the experimental LLE data. To assess the consistency of the regressed NRTL parameters, a Matlab toolbox for the topological analysis ${ }^{80}$ is employed, and the results are shown in the Supporting Information (Figures S1-S4, Supporting Information). According to the miscibility boundary analysis, the binary subsystem thiophene (2)-hydrocarbon (3) can form a homogeneous region while the binary subsystems ILs (1)-thiophene (2) and ILs (1)-hydrocarbon (3) can form a liquid-liquid region. The same conclusion can be concluded from the $G^{M} / R T$ function calculated by the correlated NRTL parameters. Moreover, the experimental observations are in line with the topological analysis. The binary subsystem $2-3$ is completely miscible while the binary subsystems $1-2$ and $1-3$ are partially miscible. This good agreement demonstrates that the NRTL parameters regressed for all the systems are reliable and can be trusted for subsequent process design.

Comparison with Other ILs. Figure 5 presents the maximum selectivity $\left(S_{23}^{\max }\right)$ of ILs at the lowest concentration of thiophene in the raffinate phase plotted against the corresponding distribution ratio $\left(\beta_{2}^{\max }\right)$ in the thiophene/ heptane system. The ILs studied in this work are compared with 48 different ILs from the literature (see the original data in Table S8, Supporting Information). ${ }^{16,18,81-98}$ Compared to other ILs, the ILs studied here have a relatively lower distribution ratio for thiophene. However, as the screening is based on $\mathrm{PI}^{\infty}$, the low distribution ratio for thiophene is largely compensated for by the high selectivity. To give a more detailed comparison, $S_{23}^{\max }$ values for each IL are sorted in ascending order and plotted in Figure 6. It can be seen that the $S_{23}^{\max }$ values of ILs are mainly determined by the anions, and the IL with the $\left[\mathrm{MESO}_{3}\right]^{-}$anion is studied for the first time in this work. The two selected ILs all have a very high $S_{23}^{\max }$, especially for [EMIM] $\left[\mathrm{MESO}_{3}\right]$, which ranks sixth among all of the ILs in the literature. Moreover, compared to the other ILs with higher selectivity, the two studied ILs have either a notably higher distribution coefficient ([IM-1,1][PO2-1,O1] and $[\mathrm{IM}-2,1][\mathrm{SCN}])$ or a simpler nonfunctionalized structure ([PYR-3CN,1][SCN], [Mo1,3CN][TCM], and [PIP-3OH,1]$[\mathrm{SCN}])$. That is to say, the ILs studied here achieve a more balanced extraction performance and are more promising in terms of easy preparation and purification. For the system of thiophene/octane, a similar finding can also be found (as shown in Table S9, Supporting Information), although the available LLE data that can be used for comparison are less than those in the case of thiophene/heptane. To summarize, the comparison with experimental LLE previously reported in the literature demonstrates the satisfactory EDS performance of the two selected ILs.

Process Simulation and Evaluation. Following the introduced method, the process performance of the two studied ILs are further evaluated and compared with that of sulfolane (a commonly used benchmark conventional solvent). The physical properties of the ILs are estimated by the built-in eqs (eqs 10-14) in Aspen Plus:

$$
\begin{aligned}
& \ln \nu=C_{1}+\frac{C_{2}}{T}+C_{3} \ln T \\
& V^{1}=C_{1}+C_{2} T \\
& C_{p}=C_{1}+C_{2} T+C_{3} T^{2}
\end{aligned}
$$



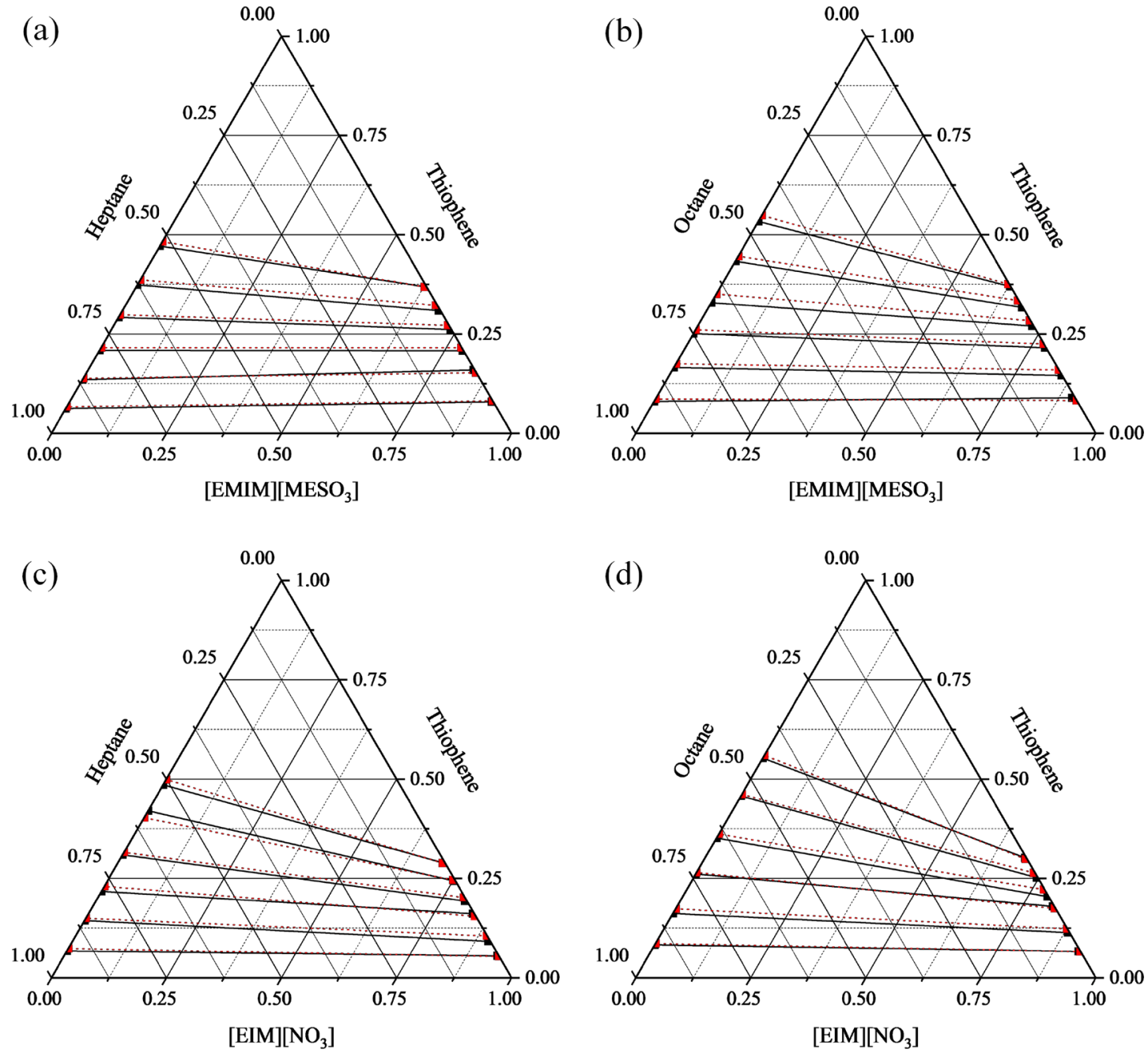

Figure 4. Tie-lines of the ternary mixture on a molar fraction basis at $298.15 \mathrm{~K}$ (black solid line for experimental data, red dashed line for NRTL correlation): (a) $\left[\right.$ EMIM] $\left[\mathrm{MESO}_{3}\right]+$ thiophene + heptane, (b) $[$ EMIM $]\left[\mathrm{MESO}_{3}\right]$ + thiophene + octane, (c) $[\mathrm{EIM}]\left[\mathrm{NO}_{3}\right]+$ thiophene + heptane, and (d) $[\mathrm{EIM}]\left[\mathrm{NO}_{3}\right]+$ thiophene + octane.

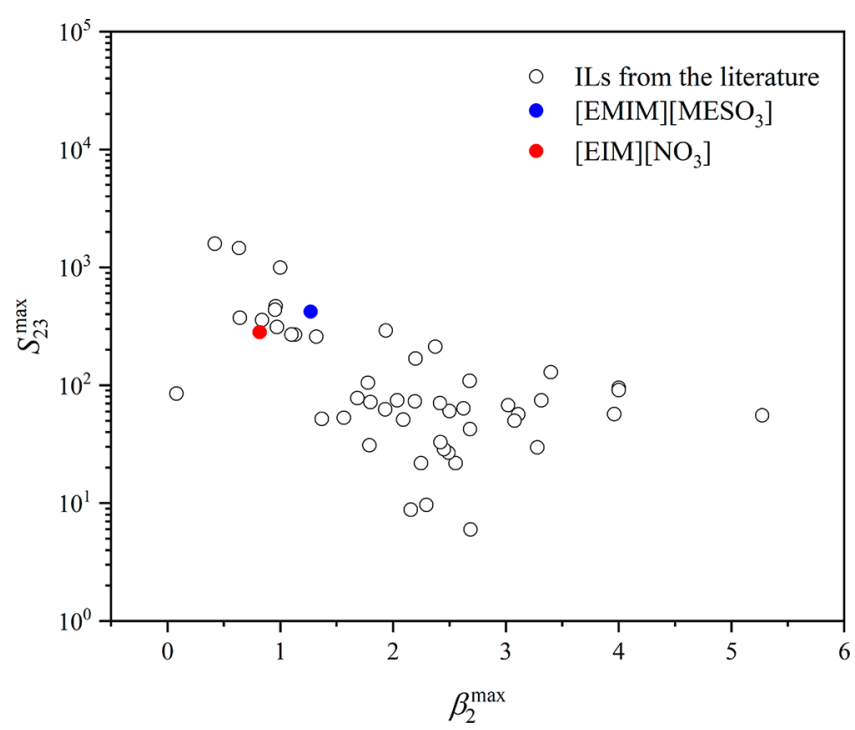

Figure 5. Comparison of the $S_{23}^{\max }$ and $\beta_{2}^{\max }$ of different ILs for the extraction of thiophene from heptane.

$$
\tau=C_{1}\left(1-T_{\mathrm{r}}\right)^{\left(C_{2}+C_{3} T+C_{4} T^{2}+C_{5} T^{2}\right)}
$$

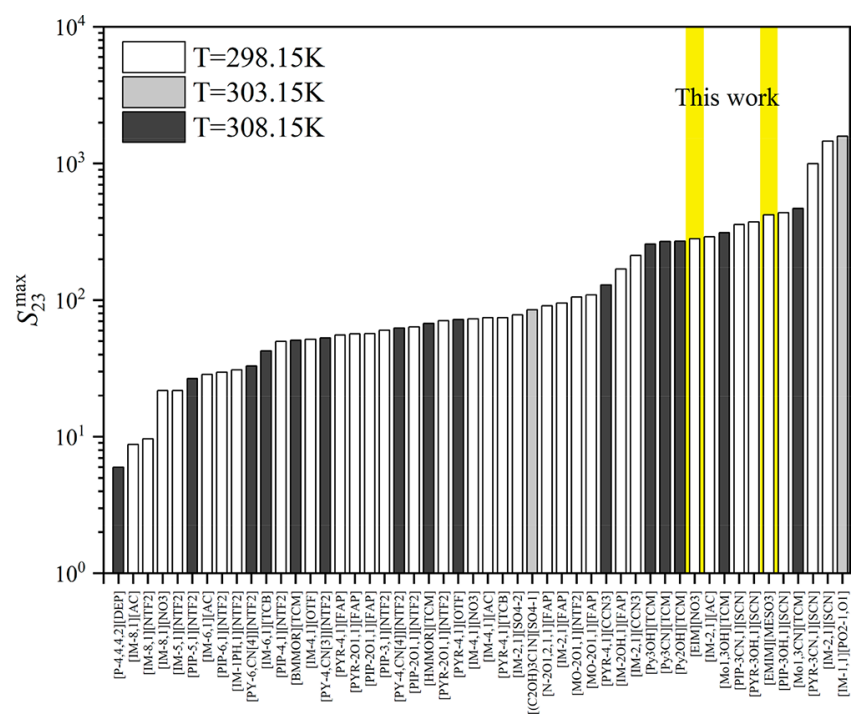

Figure 6. Comparison of experimental maximum thiophene/heptane selectivity $S_{23}^{\max }$ calculated based on LLE data reported in the literature for different ILs. 
(a)
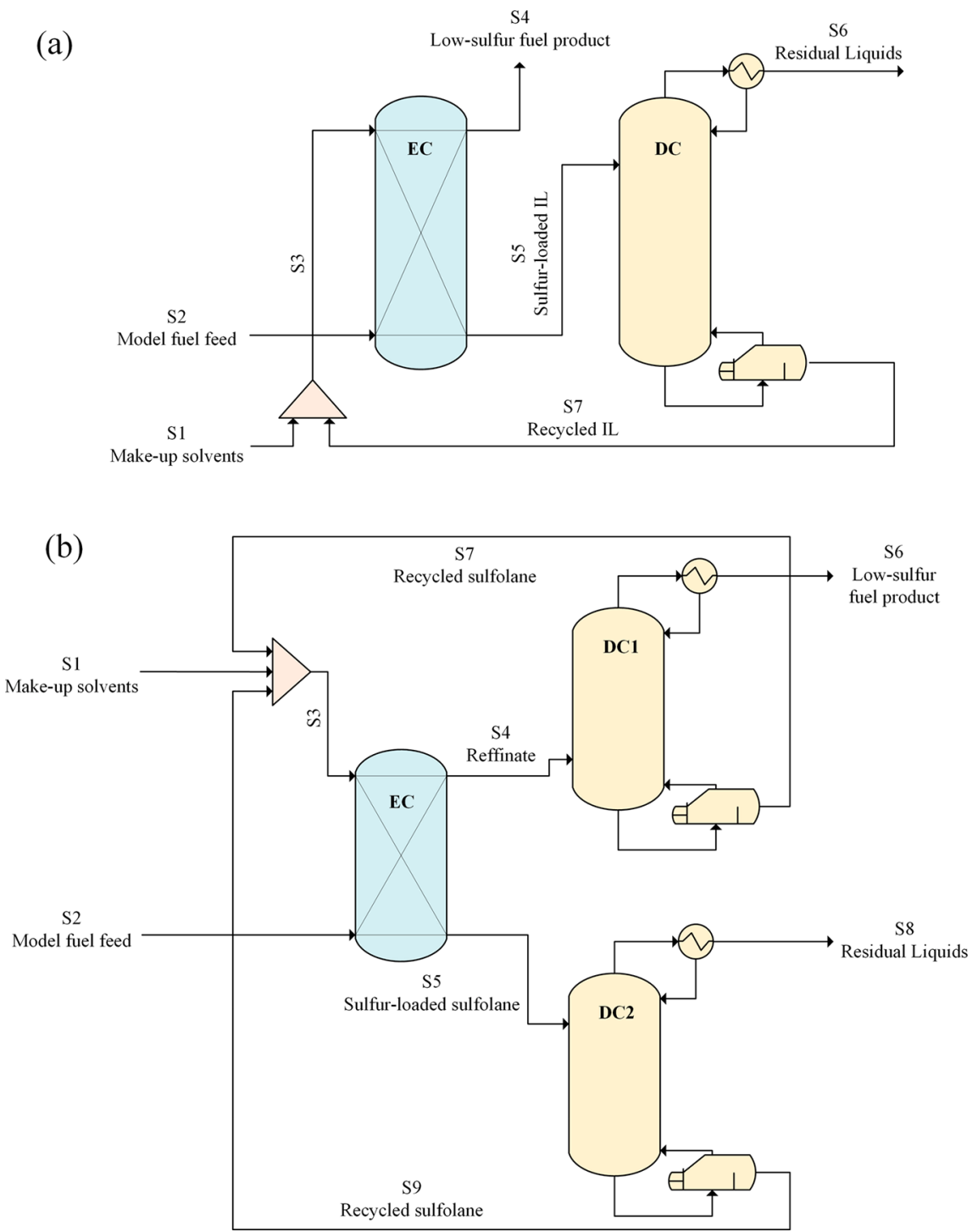

Figure 7. Continuous EDS processes using (a) ILs and (b) sulfolane as the solvent.

$$
\lambda=C_{1}+C_{2} T+C_{3} T^{2}+C_{4} T^{3}
$$

where $\nu$ is the viscosity in $\mathrm{cP}, V^{1}$ is the liquid volume in $\mathrm{m}^{3} /$ $\mathrm{kmol}, C_{\mathrm{p}}$ is the liquid heat capacity in $\mathrm{J} \mathrm{mol}^{-1} \mathrm{~K}^{-1}, \tau$ is the surface tension in $\mathrm{N} \mathrm{m}^{-1}, \lambda$ is the thermal conductivity in $\mathrm{W}$ $\mathrm{m}^{-1} \mathrm{~K}^{-1}, T_{\mathrm{r}}=T / T_{\mathcal{c}}$ and $T_{\mathrm{c}}$ is the critical temperature of IL in K.

The viscosity, ${ }^{74}$ density, ${ }^{77}$ heat capacity, ${ }^{76}$ and surface tension $^{75}$ of $[\mathrm{EMIM}]\left[\mathrm{MESO}_{3}\right]$ are calculated from the regression of experimental data (Figure S5, Supporting Information). Considering that the temperature dependence of thermal conductivity is marginal for $[\mathrm{EMIM}]\left[\mathrm{MESO}_{3}\right]$, the mean value between 300 and $375 \mathrm{~K}$ is used. ${ }^{74}$ All the regressed parameters are listed in Table S10 (Supporting Information).

As shown in Figure 7, the continuous EDS processes using the selected ILs and sulfolane as the extractant are built and compared. A feed stream of $10000 \mathrm{~kg} / \mathrm{h}$ of model fuel composed of thiophene and heptane with an initial sulfur content of $100 \mathrm{ppm}$ is fed to the bottom of the extraction column (EC). To reduce the emissions of $\mathrm{SO}_{x}$ from burning fossil fuel, the content of total sulfur compounds in the USA ${ }^{99}$ and European ${ }^{100}$ gasoline and diesel fuels is confined to a maximum concentration level of $10 \mathrm{ppm}$. Therefore, the goal of the EDS process is to reduce the sulfur content from 100 $\mathrm{ppm}$ in the fuel feed to lower than $10 \mathrm{ppm}$ in the low-sulfur fuel product.

As shown in Figure 7a, for the IL-based process, only one distillation column (DC) is needed because no IL exists in the low-sulfur stream. In contrast, the sulfolane-based process (Figure $7 \mathrm{~b}$ ) is more complicated with two DCs required, where DC1 is used for removing the dissolved sulfolane in the raffinate phase, and DC2 is used for the regeneration of sulfolane.

The key operating conditions of the EC in the IL-based and sulfolane-based processes are optimized using the sensitivity analysis. To fulfill the specification of desulfurization, the massbased solvent-to-feed ratio $(S / F)$ is determined at different numbers of stages for the studied solvents. From Figure 8, the required amount of solvent continuously decreases with the increase of the stage number, and when the stage number increased to 10 , the change of S/F can be neglected. Therefore, the stage number of EC is set to 10 for all the solvents. Compared to sulfolane, the required $\mathrm{S} / \mathrm{F}$ of the [EMIM]$\left.\mathrm{MESO}_{3}\right]$ and $[\mathrm{EIM}]\left[\mathrm{NO}_{3}\right]$ are significantly lower than that of the sulfolane. 


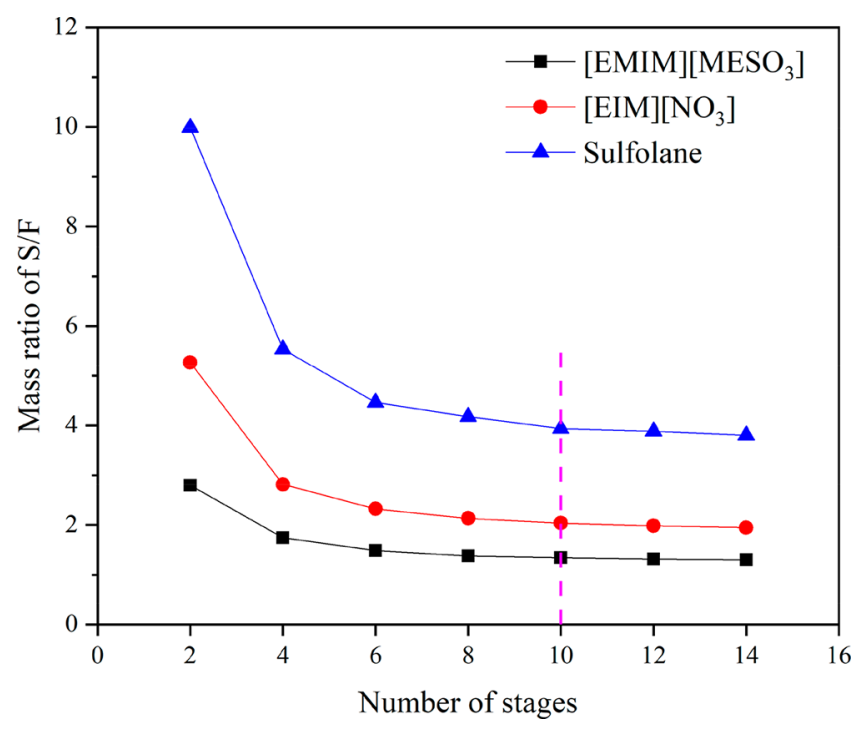

Figure 8. Mass-based solvent-to-feed ratio $(\mathrm{S} / \mathrm{F})$ versus the number of stages in the extraction column for meeting the desulfurization requirement.

To avoid using the vacuum pump, all the DCs are operated at the atmospheric pressure. For all processes, the design specification is to ensure that the sulfur content in the lowsulfur fuel product stream (S6) is $\leq 10 \mathrm{ppm}$. The optimized operating conditions and the main simulation results of the ILbased and sulfolane-based EDS processes are summarized in Table 3. It can be seen that the low-sulfur fuel products in all the processes satisfy the requirement of the sulfur content $\leq 10$ ppm. A very small amount of makeup solvent (at the level of $10^{-2} \mathrm{~kg} / \mathrm{h}$ ) is needed for the IL-based processes due to the negligible solvent loss in the EC and high solvent recovery ratio in the DC. ${ }^{101}$ In contrast, $7.09 \mathrm{~kg} / \mathrm{h}$ of sulfolane is continuously added to the sulfolane-based EDS process. The overall heat duty of the sulfolane-based process is $7966.31 \mathrm{~kW}$, which is 2.17 and 2.23 times higher than the processes using $[\mathrm{EMIM}]\left[\mathrm{MESO}_{3}\right]$ and $[\mathrm{EIM}]\left[\mathrm{NO}_{3}\right]$, respectively. It is worth mentioning that IL-based processes at the designed scale could be expected to be practical and even be scaled up in the future since many advanced commercialized IL synthesis methods have been developed, e.g., the carbonate-based IL synthesis (CBILS) method invented by Proionic (currently operating on the tonne scale). ${ }^{102,103}$

In general, due to the simpler process, less solvent consumption, and lower heat duty, the two studied ILs are promising alternatives to sulfolane for the EDS process of fuel oils. In addition, $[\mathrm{EMIM}]\left[\mathrm{MESO}_{3}\right]$ is better than [EIM]$\left[\mathrm{NO}_{3}\right]$ since the EDS process using $[\mathrm{EMIM}]\left[\mathrm{MESO}_{3}\right]$ needs a similar amount of heat duty and much less solvent compared to that of $[\mathrm{EIM}]\left[\mathrm{NO}_{3}\right]$.

\section{CONCLUSIONS}

A reliable method for the screening of practically suitable ILs as extraction solvents is presented and exemplified by the extractive desulfurization process. An experimental IDAC database is collected and used to evaluate the extraction performance measure of ILs toward the specific problem. Meanwhile, the experimental data and QSPR models are applied to assess the physical and environmental properties of ILs. ILs with potentially high performance and meeting constraints of the considered properties are selected as promising candidates. Then, the LLE experiments using these ILs are performed, and the corresponding parameters for the thermodynamic models such as NRTL are regressed. Finally, the ILs are introduced to Aspen Plus, and their performance in the continuous extraction process is compared. For the extractive desulfurization problem, [EMIM] $\left[\mathrm{MESO}_{3}\right]$ and $[\mathrm{EIM}]\left[\mathrm{NO}_{3}\right]$ are selected as the optimal solvents. The processes using these ILs have notably lower solvent consumption and heat duty compared to the benchmark process using sulfolane. These results are encouraging and demonstrate the reliability of the proposed method to screen suitable ILs for practical application.

\section{ASSOCIATED CONTENT}

\section{Supporting Information}

The Supporting Information is available free of charge at https://pubs.acs.org/doi/10.1021/acssuschemeng.0c07866.

Basic chemical information on the ILs in the IDAC database; IDAC data collected from the literature; IL screening results for desulfurization problem; results of the Hand and the Othmer-Tobias correlations; NRTL parameters regressed from the experimental LLE data; comparison of the maximum selectivity among different ILs toward the thiophene/heptane system and thiophene/octane system; parameters for the built-in equations in Aspen Plus; results of the topological analysis of NRTL correlations for (1) ILs + (2) thiophene $+(3)$ hydrocarbons; correlation results for the physical properties of $[\mathrm{EMIM}]\left[\mathrm{MESO}_{3}\right]$ based on experimental data (XLSX)

Table 3. Results Obtained from the Simulation of the Continuous EDS Processes in Aspen Plus

\begin{tabular}{|c|c|c|c|c|c|c|c|c|c|}
\hline \multirow{2}{*}{\multicolumn{3}{|c|}{ extraction column ( $298.15 \mathrm{~K}, 1$ bar, 10 stages) }} & \multicolumn{5}{|c|}{ distillation column ( 1 bar) } & & \\
\hline & & & operat & n con & ons $^{a}$ & & \multirow[b]{2}{*}{$\begin{array}{l}\text { heat duty } \\
\text { (kW) }\end{array}$} & \multicolumn{2}{|c|}{ low-sulfur fuel product } \\
\hline solvent & $\begin{array}{l}\text { recycled solvent } \\
(\mathrm{kg} / \mathrm{h})\end{array}$ & $\begin{array}{l}\text { solvent consumption } \\
(\mathrm{kg} / \mathrm{h})\end{array}$ & $D / F$ & $R$ & NS & FS & & $\begin{array}{l}\text { sulfur content } \\
(\mathrm{ppm})\end{array}$ & $\begin{array}{l}\text { recovery ratio } \\
(\%)\end{array}$ \\
\hline $\begin{array}{l}{[\mathrm{EMIM}]} \\
{\left[\mathrm{MESO}_{3}\right]}\end{array}$ & 13310 & 0.01 & $1.9 \times 10^{-04}$ & 1.2 & 10 & 2 & 3669.98 & 10 & 99.99 \\
\hline$[\mathrm{EIM}]\left[\mathrm{NO}_{3}\right]$ & 20374 & 0.05 & $1.6 \times 10^{-04}$ & 1.4 & 10 & 2 & 3568.14 & 10 & 99.99 \\
\hline \multirow[t]{2}{*}{ sulfolane } & 39516 & 7.09 & $0.98^{b}$ & $1.6^{b}$ & $10^{b}$ & $9^{b}$ & 7966.31 & 10 & 99.82 \\
\hline & & & $7 \times 10^{-04 c}$ & $0.7^{c}$ & $10^{c}$ & $2^{c}$ & & & \\
\hline
\end{tabular}

${ }^{a} D / F, R$, NS, and FS denote the mass-based distillate to feed ratio, reflux ratio, number of stages, and feed stage, respectively. ${ }^{b}$ Operating conditions for distillation column DC1. ${ }^{c}$ Operating conditions for distillation column DC2. 


\section{AUTHOR INFORMATION}

\section{Corresponding Authors}

Zhen Song - Process Systems Engineering, Otto-von-Guericke University Magdeburg, D-39106 Magdeburg, Germany;

Process Systems Engineering, Max Planck Institute for

Dynamics of Complex Technical Systems, D-39106

Magdeburg, Germany; 이이.org/0000-0001-9219-1833;

Phone: +49 3916110373; Email: songz@mpi-

magdeburg.mpg.de

Francesco Picchioni - Faculty of Science and Engineering,

University of Groningen, Groningen 9747 AG, The

Netherlands; 10 orcid.org/0000-0002-8232-2083;

Phone: +31 5036 34333; Email: f.picchioni@rug.nl

\section{Authors}

Daili Peng - Faculty of Science and Engineering, University of Groningen, Groningen 9747 AG, The Netherlands

Anne-Jan Kleiweg - Faculty of Science and Engineering, University of Groningen, Groningen 9747 AG, The Netherlands

Jozef G. M. Winkelman - Faculty of Science and Engineering, University of Groningen, Groningen 9747 AG, The

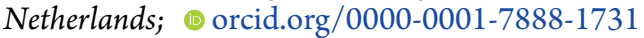

Complete contact information is available at:

https://pubs.acs.org/10.1021/acssuschemeng.0c07866

\section{Notes}

The authors declare no competing financial interest.

\section{ACKNOWLEDGMENTS}

We are grateful for the financial support provided by the China Scholarship Council (No. 201606740070).

\section{NOMENCLATURE}

$\beta_{i}^{\infty}=$ distribution coefficient of component $i$ at infinite dilution

$\beta_{i}=$ distribution coefficient of component $i$

$E=$ extract phase

$\mathrm{PI}^{\infty}=$ performance index of extraction at infinite dilution

$R=$ raffinate phase

$S_{i j}^{\infty}=$ infinite dilution selectivity of solvent to the component $i$ over $j$

$S_{i j}=$ selectivity of solvent to the component $i$ over $j$

$x_{i}=$ molar composition of component $i$ in liquid

$w_{i}=$ mass composition of component $i$ in liquid

$\gamma_{i}^{\infty}=$ infinite dilution activity coefficient of component $i$

[BMMOR] = 1-butyl-1-methylmorpholinium

[EIM $]=1$-ethylimidazolium

[EMIM $]=1$-ethyl-3-methylimidazolium

[HMMOR $]=1$-hexyl-1-methylmorpholinium

$[\mathrm{IM}-1,1]=1,3$-dimethylimidazolium

[IM-1PH,1] = 1-benzyl-3-methylimidazolium

[IM-2,1] = 1-ethyl-3-methylimidazolium

[IM-2OH,1] = 1-(2-hydroxyethyl)-3-methylimidazolium

[IM-4,1] = 1-butyl-3-methylimidazolium

[IM-5,1] = 3-methyl-1-pentylimidazolium

[IM-6,1] = 3-hexyl-1-methylimidazolium

[IM-8,1] = 1-octyl-3-methylimidazolium

$[\mathrm{Mo} 1,3 \mathrm{CN}]=\mathrm{N}$-(3-cyanopropyl)- $\mathrm{N}$-methylmorpholinium

$[\mathrm{Mo1}, 3 \mathrm{OH}]=\mathrm{N}$-(3-hydroxypropyl)- $\mathrm{N}$-methylmorpholinium

$[\mathrm{MO}-2 \mathrm{O} 1,1]=4$-(2-methoxyethyl)-4-methylmorpholinium
$[\mathrm{N}-2 \mathrm{O} 1,2,1,1]=$ ethyl $(2$-methoxyethyl)dimethylammonium $[\mathrm{N}-2 \mathrm{OH}, 2 \mathrm{OH}, 2 \mathrm{OH}, 1]=\operatorname{tris}(2$-hydroxyethyl $)-$ (methyl)ammonium

[OHOHIM $]$ = 1,3-dihydrox1,3-dihydroxyimidazoliumyimidazolium

$[P \overline{4}, 4,4,2]=$ tributyl (ethyl)phosphonium

$[\mathrm{Pi} 4, \mathrm{i} 4, \mathrm{i} 4,1]=\operatorname{tri}($ iso-butyl) methylphosphonium

$[\mathrm{PIP}-2 \mathrm{O} 1,1]=1-(2$-methoxyethyl $)-1$-methylpiperidinium

[PIP-3,1] = 1-methyl-1-propylpiperidinium

[PIP-3CN,1] = 1-(3-cyanopropyl)-1-methylpiperidinium

[PIP-3OH,1] = 1-(3-hydroxypropyl)-1-methylpiperidinium

[PIP-4,1] = 1-Butyl-1-methylpiperidinium

[PIP-5,1] = 1-methyl-1-pentylpiperidinium

[PIP-6,1] = 1-hexyl-1-methylpiperidinium

$[\mathrm{PO} 2-\mathrm{O} 2, \mathrm{O} 2]=$ diethyl phosphate

$[\mathrm{Py} 2 \mathrm{OH}]=\mathrm{N}-(2$-hydroxyethyl)pyridinium

$[\mathrm{Py} 3 \mathrm{CN}]=\mathrm{N}-(3$-cyanopropyl $)$ pyridinium

$[\mathrm{Py} 3 \mathrm{OH}]=\mathrm{N}$-(3-hydroxypropyl)pyridinium

$[\mathrm{PY}-4, \mathrm{CN}[3]]=3$-cyano-1-butylpyridinium

$[\mathrm{PY}-4, \mathrm{CN}[4]]=4$-cyano-1-butylpyridinium

$[\mathrm{PY}-6, \mathrm{CN}[4]]=$ 4-cyano-1-hexylpyridinium

$[$ PYR-2O1,1] = 1-(2- methoxyethyl)-1-methylpyrrolidinium

[PYR-3CN,1] = 1-(3-cyanopropyl)-1-methylpyrrolidinium

[PYR-3OH,1 $]=1$-(3-hydroxypropyl)-1-methylpyrrolidinium

[PYR-4,1] = 1-butyl-1-methylpyrrolidinium

$[\mathrm{AC}]=$ acetate

[CCN3] = tricyanomethanide

$[\mathrm{DCA}]=$ dicyanamide

$[\mathrm{FAP}]=$ trifluorotris (pentafluoroethyl)phospha

[MESO3 $]=$ methanesulfonate

[NO3] $=$ nitrate

[NTF2] = bis(trifluoromethylsulfonyl)imid

$[\mathrm{OTF}]=$ trifluoromethanesulfonat

$[\mathrm{PO} 2-1, \mathrm{O} 1]=$ methylphosphonate

$[\mathrm{SCN}]=$ thiocyanate

[SO4-1] = methyl sulfate

[SO4-2] = ethyl sulfate

$[\mathrm{TCB}]=$ tetracyanoborate

$[\mathrm{TCM}]=$ tricyanomethanide

$[\mathrm{TOS}]=$ tosylate

\section{REFERENCES}

(1) Huang, K.; Zhang, X.-M.; Zhou, L.-S.; Tao, D.-J.; Fan, J.-P. Highly Efficient and Selective Absorption of $\mathrm{H}_{2} \mathrm{~S}$ in Phenolic Ionic Liquids: A Cooperative Result of Anionic Strong Basicity and Cationic Hydrogen-Bond Donation. Chem. Eng. Sci. 2017, 173, 253263.

(2) Huang, K.; Zhang, J.-Y.; Hu, X.-B.; Wu, Y.-T. Absorption of $\mathrm{H}_{2} \mathrm{~S}$ and $\mathrm{CO}_{2}$ in Aqueous Solutions of Tertiary-Amine Functionalized Protic Ionic Liquids. Energy Fuels 2017, 31 (12), 14060-14069.

(3) Liu, F.; Huang, K.; Jiang, L. Promoted Adsorption of $\mathrm{CO}_{2}$ on Amine-Impregnated Adsorbents by Functionalized Ionic Liquids. AIChE J. 2018, 64 (10), 3671-3680.

(4) Wang, Y.; Liu, X.; Kraslawski, A.; Gao, J.; Cui, P. A Novel Process Design for $\mathrm{CO}_{2}$ Capture and $\mathrm{H}_{2} \mathrm{~S}$ Removal from the Syngas Using Ionic Liquid. J. Cleaner Prod. 2019, 213, 480-490.

(5) Yu, G.; Dai, C.; Gao, H.; Zhu, R.; Du, X.; Lei, Z. Capturing Condensable Gases with Ionic Liquids. Ind. Eng. Chem. Res. 2018, 57 (36), 12202-12214.

(6) Zhu, Z.; Xu, Y.; Li, H.; Shen, Y.; Meng, D.; Cui, P.; Ma, Y.; Wang, Y.; Gao, J. Separation of Isopropyl Alcohol and Isopropyl Ether with Ionic Liquids as Extractant Based on Quantum Chemical Calculation and Liquid-Liquid Equilibrium Experiment. Sep. Purif. Technol. 2020, 247, 116937-116945. 
(7) Wang, Y.; Yang, X.; Bai, W.; Zhang, J.; Zhou, X.; Guo, X.; Peng, J.; Qi, J.; Zhu, Z. Screening of Imidazole Ionic Liquids for Separating the Acetone-n-Hexane Azeotrope by COSMO-SAC Simulations and Experimental Verification. ACS Sustainable Chem. Eng. 2020, 8 (11), $4440-4450$

(8) Wang, P.; Xu, D.; Yan, P.; Gao, J.; Zhang, L.; Wang, Y. Separation of Azeotrope (Ethanol and Ethyl Methyl Carbonate) by Different Imidazolium-Based Ionic Liquids: Ionic Liquids Interaction Analysis and Phase Equilibrium Measurements. J. Mol. Liq. 2018, 261, 89-95.

(9) Dong, Y.; Dai, C.; Lei, Z. Extractive Distillation of Methylal/ Methanol Mixture Using the Mixture of Dimethylformamide (DMF) and Ionic Liquid as Entrainers. Fuel 2018, 216, 503-512.

(10) Lei, Z.; Xi, X.; Dai, C.; Zhu, J.; Chen, B. Extractive Distillation with the Mixture of Ionic Liquid and Solid Inorganic Salt as Entrainers. AIChE J. 2014, 60 (8), 2994-3004.

(11) Lyu, Z.; Zhou, T.; Chen, L.; Ye, Y.; Sundmacher, K.; Qi, Z. Reprint of: Simulation Based Ionic Liquid Screening for BenzeneCyclohexane Extractive Separation. Chem. Eng. Sci. 2014, 115, 186194.

(12) Zhou, T.; Wang, Z.; Ye, Y.; Chen, L.; Xu, J.; Qi, Z. Deep Separation of Benzene from Cyclohexane by Liquid Extraction Using Ionic Liquids as the Solvent. Ind. Eng. Chem. Res. 2012, 51 (15), $5559-5564$

(13) Zhou, T.; Wang, Z.; Chen, L.; Ye, Y.; Qi, Z.; Freund, H.; Sundmacher, K. Evaluation of the Ionic Liquids 1-Alkyl-3Methylimidazolium Hexafluorophosphate as a Solvent for the Extraction of Benzene from Cyclohexane: (Liquid + Liquid) Equilibria. J. Chem. Thermodyn. 2012, 48, 145-149.

(14) Qin, L.; Zhang, J.; Cheng, H.; Chen, L.; Qi, Z.; Yuan, W. Selection of Imidazolium-Based Ionic Liquids for Vitamin e Extraction from Deodorizer Distillate. ACS Sustainable Chem. Eng. 2016, 4 (2), 583-590.

(15) Martins, M. A. R.; Domańska, U.; Schröder, B.; Coutinho, J. A. P.; Pinho, S. P. Selection of Ionic Liquids to Be Used as Separation Agents for Terpenes and Terpenoids. ACS Sustainable Chem. Eng. 2016, 4 (2), 548-556.

(16) Kȩdra-Krolik, K.; Mutelet, F.; Moïse, J.-C.; Jaubert, J.-N. Deep Fuels Desulfurization and Denitrogenation Using 1-Butyl-3-Methylimidazolium Trifluoromethanesulfonate. Energy Fuels 2011, 25 (4), $1559-1565$.

(17) Hansmeier, A. R.; Meindersma, G. W.; de Haan, A. B. Desulfurization and Denitrogenation of Gasoline and Diesel Fuels by Means of Ionic Liquids. Green Chem. 2011, 13, 1907-1913.

(18) Paduszyński, K.; Królikowski, M.; Zawadzki, M.; Orzeł, P. Computer-Aided Molecular Design of New Task-Specific Ionic Liquids for Extractive Desulfurization of Gasoline. ACS Sustainable Chem. Eng. 2017, 5 (10), 9032-9042.

(19) Song, Z.; Zhang, C.; Qi, Z.; Zhou, T.; Sundmacher, K. Computer-Aided Design of Ionic Liquids as Solvents for Extractive Desulfurization. AIChE J. 2018, 64 (3), 1013-1025.

(20) Song, Z.; Zhou, T.; Qi, Z.; Sundmacher, K. Systematic Method for Screening Ionic Liquids as Extraction Solvents Exemplified by an Extractive Desulfurization Process. ACS Sustainable Chem. Eng. 2017, 5 (4), 3382-3389.

(21) Huang, Y.; Dong, H.; Zhang, X.; Li, C.; Zhang, S. A New Fragment Contribution-Corresponding States Method for Physicochemical Properties Prediction of Ionic Liquids. AIChE J. 2013, 59 (4), 1348-1359.

(22) Lei, Z.; Chen, B.; Li, C. COSMO-RS Modeling on the Extraction of Stimulant Drugs from Urine Sample by the Double Actions of Supercritical Carbon Dioxide and Ionic Liquid. Chem. Eng. Sci. 2007, 62 (15), 3940-3950.

(23) Sandler, S. I. Infinite Dilution Activity Coefficients in Chemical, Environmental and Biochemical Engineering. Fluid Phase Equilib. 1996, 116 (1-2), 343-353.

(24) Song, Z.; Zhou, T.; Zhang, J.; Cheng, H.; Chen, L.; Qi, Z. Screening of Ionic Liquids for Solvent-Sensitive Extraction - with
Deep Desulfurization as an Example. Chem. Eng. Sci. 2015, 129, 6977.

(25) Anantharaj, R.; Banerjee, T. COSMO-RS-Based Screening of Ionic Liquids as Green Solvents in Denitrification Studies. Ind. Eng. Chem. Res. 2010, 49 (18), 8705-8725.

(26) Salleh, M. Z. M.; Hadj-Kali, M. K.; Hashim, M. A.; Mulyono, S. Ionic Liquids for the Separation of Benzene and Cyclohexane COSMO-RS Screening and Experimental Validation. J. Mol. Liq. 2018, 266, 51-61.

(27) Domańska, U.; Wlazło, M.; Karpińska, M.; Zawadzki, M. Separation of Binary Mixtures Hexane/Hex-1-Ene, Cyclohexane/ Cyclohexene and Ethylbenzene/Styrene Based on Limiting Activity Coefficients. J. Chem. Thermodyn. 2017, 110, 227-236.

(28) Lei, Z.; Zhang, J.; Li, Q.; Chen, B. UNIFAC Model for Ionic Liquids. Ind. Eng. Chem. Res. 2009, 48 (5), 2697-2704.

(29) Song, Z.; Zhou, T.; Qi, Z.; Sundmacher, K. Extending the UNIFAC Model for Ionic Liquid-Solute Systems by Combining Experimental and Computational Databases. AIChE J. 2020, 66 (2), e16821.

(30) Haghtalab, A.; Paraj, A. Computation of Liquid-Liquid Equilibrium of Organic-Ionic Liquid Systems Using NRTL, UNIQUAC and NRTL-NRF Models. J. Mol. Liq. 2012, 171, 43-49.

(31) Paduszyński, K.; Lukoshko, E. V.; Królikowski, M.; Domańska, U.; Szydłowski, J. Thermodynamic Study of Binary Mixtures of 1Butyl-1-Methylpyrrolidinium Dicyanamide Ionic Liquid with Molecular Solvents: New Experimental Data and Modeling with PC-Saft Equation of State. J. Phys. Chem. B 2015, 119 (2), 543-551.

(32) Klamt, A.; Eckert, F. COSMO-RS: A Novel and Efficient Method for the a Priori Prediction of Thermophysical Data of Liquids. Fluid Phase Equilib. 2000, 172 (1), 43-72.

(33) Lin, S.-T.; Sandler, S. I. A Priori Phase Equilibrium Prediction from a Segment Contribution Solvation Model. Ind. Eng. Chem. Res. 2002, 41 (5), 899-913.

(34) Brouwer, T.; Schuur, B. Model Performances Evaluated for Infinite Dilution Activity Coefficients Prediction at 298.15 K. Ind. Eng. Chem. Res. 2019, 58 (20), 8903-8914.

(35) Zhu, Z.; Li, H.; Xu, Y.; Zhang, W.; Shen, Y.; Gao, J.; Wang, L.; Wang, Y. Quantum Chemical Calculation, Molecular Dynamics Simulation and Process Design for Separation of Heptane - Butanol Using Ionic Liquids Extraction. J. Mol. Liq. 2020, 316, 113851113858.

(36) Zhang, W.; Chen, Z.; Shen, Y.; Li, G.; Dai, Y.; Qi, J.; Ma, Y.; Yang, S.; Wang, Y. Molecular Mechanism and Extraction Performance Evaluation for Separation of Methanol and N-Hexane via Ionic Liquids as Extractant. ACS Sustainable Chem. Eng. 2020, 8 (23), $8700-8712$.

(37) Xu, Y.; Meng, D.; Li, H.; Yu, X.; Zhu, Z.; Wang, Y.; Ma, Y.; Gao, J. Mechanism Analysis for Separation of Cyclohexane and TertButanol System via Ionic Liquids as Extractants and Process Optimization. ACS Sustainable Chem. Eng. 2019, 7 (24), 1998419992.

(38) Everett, D. H. Effect of Gas Imperfection on G.L.C. Measurements: A Refined Method for Determining Activity Coefficients and Second Virial Coefficients. Trans. Faraday Soc. 1965, 61, 1637-1645.

(39) Cruickshank, A. J. B.; Gainey, B. W.; Hicks, C. P.; Letcher, T. M.; Moody, R. W.; Young, C. L. Gas-Liquid Chromatographic Determination of Cross-Term Second Virial Coefficients Using Glycerol Benzene + Nitrogen and Benzene + Carbon Dioxide at $50^{\circ}$ C. Trans. Faraday Soc. 1969, 65, 1014-1031.

(40) Domańska, U.; Królikowski, M. Measurements of Activity Coefficients at Infinite Dilution for Organic Solutes and Water in the Ionic Liquid 1-Ethyl-3-Methylimidazolium Methanesulfonate. J. Chem. Thermodyn. 2012, 54, 20-27.

(41) Paduszyński, K. An Overview of the Performance of the COSMO-RS Approach in Predicting the Activity Coefficients of Molecular Solutes in Ionic Liquids and Derived Properties at Infinite Dilution. Phys. Chem. Chem. Phys. 2017, 19, 11835-11850. 
(42) Liu, X.; Chen, Y.; Zeng, S.; Zhang, X.; Zhang, S.; Liang, X.; Gani, R.; Kontogeorgis, G. M. Structure Optimization of Tailored Ionic Liquids and Process Simulation for Shale Gas Separation. AIChE J. 2020, 66 (2), 1-14.

(43) Ventura, S. P. M.; Gonçalves, A. M. M.; Sintra, T.; Pereira, J. L.; Gonçalves, F.; Coutinho, J. A. P. Designing Ionic Liquids: The Chemical Structure Role in the Toxicity. Ecotoxicology 2013, 22 (1), $1-12$.

(44) Karunanithi, A. T.; Mehrkesh, A. Computer-Aided Design of Tailor-Made Ionic Liquids. AIChE J. 2013, 59 (12), 4627-4640.

(45) Wang, J.; Song, Z.; Cheng, H.; Chen, L.; Deng, L.; Qi, Z. Computer-Aided Design of Ionic Liquids as Absorbent for Gas Separation Exemplified by $\mathrm{CO}_{2}$ Capture Cases. ACS Sustainable Chem. Eng. 2018, 6 (9), 12025-12035.

(46) Song, Z.; Zhou, T.; Qi, Z.; Sundmacher, K. Systematic Method for Screening Ionic Liquids as Extraction Solvents Exemplified by an Extractive Desulfurization Process. ACS Sustainable Chem. Eng. 2017, 5 (4), 3382-3389.

(47) Zhang, J.; Qin, L.; Peng, D.; Zhou, T.; Cheng, H.; Chen, L.; Qi, Z. COSMO-Descriptor Based Computer-Aided Ionic Liquid Design for Separation Processes: Part II: Task-Specific Design for Extraction Processes. Chem. Eng. Sci. 2017, 162, 364-374.

(48) Peng, D.; Zhang, J.; Cheng, H.; Chen, L.; Qi, Z. ComputerAided Ionic Liquid Design for Separation Processes Based on Group Contribution Method and COSMO-SAC Model. Chem. Eng. Sci. 2017, 159, 58-68.

(49) Song, Z.; Zhou, T.; Zhang, J.; Cheng, H.; Chen, L.; Qi, Z. Screening of Ionic Liquids for Solvent-Sensitive Extraction -with Deep Desulfurization as an Example. Chem. Eng. Sci. 2015, 129, 69-77.

(50) Pernak, J.; Borucka, N.; Walkiewicz, F.; Markiewicz, B.; Fochtman, P.; Stolte, S.; Steudte, S.; Stepnowski, P. Synthesis, Toxicity, Biodegradability and Physicochemical Properties of 4Benzyl-4-Methylmorpholinium-Based Ionic Liquids. Green Chem. 2011, 13 (10), 2901-2910.

(51) Ranke, J.; Müller, A.; Bottin-Weber, U.; Stock, F.; Stolte, S.; Arning, J.; Störmann, R.; Jastorff, B. Lipophilicity Parameters for Ionic Liquid Cations and Their Correlation to in Vitro Cytotoxicity. Ecotoxicol. Environ. Saf. 2007, 67 (3), 430-438.

(52) Stolte, S.; Schulz, T.; Cho, C.-W.; Arning, J.; Strassner, T. Synthesis, Toxicity, and Biodegradation of Tunable Aryl Alkyl Ionic Liquids (TAAILs). ACS Sustainable Chem. Eng. 2013, 1 (4), 410418.

(53) Peng, D.; Picchioni, F. Prediction of Toxicity of Ionic Liquids Based on GC-COSMO Method. J. Hazard. Mater. 2020, 398, 122964-122975.

(54) Lazzús, J. A. A Group Contribution Method to Predict the Melting Point of Ionic Liquids. Fluid Phase Equilib. 2012, 313, 1-6.

(55) Paduszynski, K. Extensive Databases and Group Contribution QSPRs of Ionic Liquids Properties. 2. Viscosity. Ind. Eng. Chem. Res. 2019, 58, 17049-17066.

(56) McLeese, S. E.; Eslick, J. C.; Hoffmann, N. J.; Scurto, A. M.; Camarda, K. V. Design of Ionic Liquids via Computational Molecular Design. Comput. Chem. Eng. 2010, 34 (9), 1476-1480.

(57) Hand, D. B. Dineric Distribution. J. Phys. Chem. 1930, 34 (9), 1961-2000.

(58) Othmer, D.; Tobias, P. Liquid-Liquid Extraction Data - The Line Correlation. Ind. Eng. Chem. 1942, 34 (6), 693-696.

(59) Renon, H.; Prausnitz, J. M. Local Compositions in Thermodynamic Excess Functions for Liquid Mixtures. AIChE J. 1968, 14 (1), 135-144.

(60) Paduszynski, K. Extensive Databases and Group Contribution QSPRs of Ionic Liquids Properties. 2. Viscosity. Ind. Eng. Chem. Res. 2019, 58, 17049-17066.

(61) Paduszynski, K. Extensive Databases and Group Contribution QSPRs of Ionic Liquids Properties. 1. Density. Ind. Eng. Chem. Res. 2019, 58 (13), 5322-5338.

(62) Ahmadi, A.; Haghbakhsh, R.; Raeissi, S.; Hemmati, V. A Simple Group Contribution Correlation for the Prediction of Ionic Liquid
Heat Capacities at Different Temperatures. Fluid Phase Equilib. 2015, 403, 95-103.

(63) Lazzus, J. A.; Cuturrufo, F.; Pulgar-Villarroel, G.; Salfate, I.; Vega, P. Estimating the Temperature-Dependent Surface Tension of Ionic Liquids Using a Neural Network-Based Group Contribution Method. Ind. Eng. Chem. Res. 2017, 56 (23), 6869-6886.

(64) Oster, K.; Jacquemin, J.; Hardacre, C.; Ribeiro, A. P. C.; Elsinawi, A. Further Development of the Predictive Models for Physical Properties of Pure Ionic Liquids: Thermal Conductivity and Heat Capacity. J. Chem. Thermodyn. 2018, 118, 1-15.

(65) Valderrama, J. J.; Forero, L. A.; Rojas, R. E. Critical Properties and Normal Boiling Temperature of Ionic Liquids. Update and a New Consistency Test. Ind. Eng. Chem. Res. 2012, 51 (22), 7838-7844.

(66) Ferro, V. R.; Ruiz, E.; Tobajas, M.; Palomar, J. F. Integration of COSMO-Based Methodologies into Commercial Process Simulators: Separation and Purification of Reuterin. AIChE J. 2012, 58 (11), 3404-3415.

(67) Ferro, V. R.; Ruiz, E.; De Riva, J.; Palomar, J. Introducing Process Simulation in Ionic Liquids Design/Selection for Separation Processes Based on Operational and Economic Criteria through the Example of Their Regeneration. Sep. Purif. Technol. 2012, 97, 195204.

(68) De Riva, J.; Ferro, V. R.; Moreno, D.; Diaz, I.; Palomar, J. Aspen Plus Supported Conceptual Design of the Aromatic-Aliphatic Separation from Low Aromatic Content Naphtha Using 4-Methyl-NButylpyridinium Tetrafluoroborate Ionic Liquid. Fuel Process. Technol. 2016, 146, 29-38.

(69) Xie, Y.; Ma, C.; Lu, X.; Ji, X. Evaluation of Imidazolium-Based Ionic Liquids for Biogas Upgrading. Appl. Energy 2016, 175, 69-81.

(70) Aranowski, R.; Cichowska-Kopczyńska, I.; Dębski, B.; Jasiński, P. Conductivity and Viscosity Changes of Imidazolium Ionic Liquids Induced by $\mathrm{H}_{2} \mathrm{O}$ and $\mathrm{CO}_{2}$. J. Mol. Liq. 2016, 221, 541-546.

(71) Stejfa, V.; Rohlíček, J.; Cervinka, C. Phase Behaviour and Heat Capacities of Selected 1-Ethyl-3-Methylimidazolium-Based Ionic Liquids. J. Chem. Thermodyn. 2020, 142, 106020-106029.

(72) Pajajk, M.; Hubkowska, K.; Czerwiński, A. Nitrate Protic Ionic Liquids as Electrolytes: Towards Hydrogen Sorption in Pd. Electrochim. Acta 2019, 324, 134851-134860.

(73) Greer, A. J.; Jacquemin, J.; Hardacre, C. Industrial Applications of Ionic Liquids. Molecules 2020, 25 (21), 5207-5237.

(74) Tenney, C. M.; Massel, M.; Mayes, J. M.; Sen, M.; Brennecke, J. F.; Maginn, E. J. A Computational and Experimental Study of the Heat Transfer Properties of Nine Different Ionic Liquids. J. Chem. Eng. Data 2014, 59 (2), 391-399.

(75) Almeida, H. F. D.; Teles, A. R. R.; Lopes-da-Silva, J. A.; Freire, M. G.; Coutinho, J. A. P. Influence of the Anion on the Surface Tension of 1-Ethyl-3-Methylimidazolium-Based Ionic Liquids. J. Chem. Thermodyn. 2012, 54, 49-54.

(76) Musiał, M.; Zorębski, M.; Dzida, M.; Safarov, J.; Zorębski, E.; Hassel, E. High Pressure Speed of Sound and Related Properties of 1ethyl-3-methylimidazolium Methanesulfonate. J. Mol. Liq. 2019, 276, 885-896.

(77) Freire, M. G.; Teles, A. R. R.; Rocha, M. A. A.; Schröder, B.; Neves, C. M. S. S.; Carvalho, P. J.; Evtuguin, D. V.; Santos, L. M. N. B. F.; Coutinho, J. A. P. Thermophysical Characterization of Ionic Liquids Able To Dissolve Biomass. J. Chem. Eng. Data 2011, 56 (12), $4813-4822$.

(78) Zhao, H.; Baker, G. A.; Wagle, D. V.; Ravula, S.; Zhang, Q. Tuning Task-Specific Ionic Liquids for the Extractive Desulfurization of Liquid Fuel. ACS Sustainable Chem. Eng. 2016, 4 (9), 4771-4780.

(79) Gao, H.; Zeng, S.; Liu, X.; Nie, Y.; Zhang, X.; Zhang, S. Extractive Desulfurization of Fuel Using N-Butylpyridinium-Based Ionic Liquids. RSC Adv. 2015, 5 (38), 30234-30238.

(80) Marcilla, A.; Reyes-Labarta, J. A.; Olaya, M. M. Should We Trust All the Published LLE Correlation Parameters in Phase Equilibria? Necessity of Their Assessment Prior to Publication. Fluid Phase Equilib. 2017, 433, 243-252.

(81) Królikowski, M.; Walczak, K.; Domańska, U. Solvent Extraction of Aromatic Sulfur Compounds from N-Heptane Using the 1-Ethyl-3- 
Methylimidazolium Tricyanomethanide Ionic Liquid. J. Chem. Thermodyn. 2013, 65, 168-173.

(82) Mokhtarani, B.; Mansourzareh, H.; Mortaheb, H. R. Phase Behavior of Nitrate Based Ionic Liquids with Thiophene and Alkanes. Ind. Eng. Chem. Res. 2014, 53 (3), 1256-1261.

(83) Song, Z.; Zhang, J.; Zeng, Q.; Cheng, H.; Chen, L.; Qi, Z. Effect of Cation Alkyl Chain Length on Liquid-Liquid Equilibria of \{ionic Liquids + Thiophene + Heptane : COSMO-RS Prediction and Experimental Verification. Fluid Phase Equilib. 2016, 425, 244-251.

(84) Królikowski, M.; Więckowski, M.; Zawadzki, M. Separation of Organosulfur Compounds from Heptane by Liquid-Liquid Extraction with Tricyanomethanide Based Ionic Liquids. Experimental Data and NRTL Correlation. J. Chem. Thermodyn. 2020, 149, 106149106166.

(85) Królikowski, M. Liquid-Liquid Extraction of Sulfur Compounds from Heptane with Tricyanomethanide Based Ionic Liquids. J. Chem. Thermodyn. 2019, 131, 460-470.

(86) Rogošić, M.; Sander, A.; Pantaler, M. Application of 1-Pentyl-3Methylimidazolium Bis(Trifluoromethylsulfonyl) Imide for Desulfurization, Denitrification and Dearomatization of FCC Gasoline. J. Chem. Thermodyn. 2014, 76, 1-15.

(87) Alonso, L.; Arce, A.; Francisco, M.; Soto, A. Phase Behaviour of 1-Methyl-3-Octylimidazolium Bis[Trifluoromethylsulfonyl]Imide with Thiophene and Aliphatic Hydrocarbons: The Influence of $\mathrm{n}$ Alkane Chain Length. Fluid Phase Equilib. 2008, 263 (2), 176-181.

(88) Kedra-Krolik, K.; Fabrice, M.; Jaubert, J.-N. Extraction of Thiophene or Pyridine from N-Heptane Using Ionic Liquids. Gasoline and Diesel Desulfurization. Ind. Eng. Chem. Res. 2011, 50 (4), 2296-2306.

(89) Marciniak, A.; Królikowski, M. Ternary Liquid-Liquid Equilibria of Bis(Trifluoromethylsulfonyl)-Amide Based Ionic Liquids+thiophene $+\mathrm{n}-$ Heptane. The Influence of Cation Structure. Fluid Phase Equilib. 2012, 321, 59-63.

(90) Domańska, U.; Walczak, K.; Królikowski, M. Extraction Desulfurization Process of Fuels with Ionic Liquids. J. Chem. Thermodyn. 2014, 77, 40-45.

(91) Wlazło, M.; Ramjugernath, D.; Naidoo, P.; Domańska, U. Effect of the Alkyl Side Chain of the 1-Alkylpiperidinium-Based Ionic Liquids on Desulfurization of Fuels. J. Chem. Thermodyn. 2014, 72, 31-36.

(92) Marciniak, A.; Wlazło, M. Ternary (Liquid + Liquid) Equilibria of \{trifluorotris(Perfluoroethyl)Phosphate Based Ionic Liquids + Thiophene + Heptane\}: Part 2. J. Chem. Thermodyn. 2015, 86, 196201.

(93) Alonso, L.; Arce, A.; Francisco, M.; Soto, A. Thiophene Separation from Aliphatic Hydrocarbons Using the 1-Ethyl-3Methylimidazolium Ethylsulfate Ionic Liquid. Fluid Phase Equilib. 2008, 270 (1-2), 97-102.

(94) Domańska, U.; Walczak, K.; Zawadzki, M. Separation of Sulfur Compounds from Alkanes with 1-Alkylcyanopyridinium-Based Ionic Liquids. J. Chem. Thermodyn. 2014, 69, 27-35.

(95) Marciniak, A.; Królikowski, M. Ternary (Liquid+liquid) Equilibria of \{trifluorotris(Perfluoroethyl)Phosphate Based Ionic Liquidstthiophene+heptane\}. J. Chem. Thermodyn. 2012, 49, 154158.

(96) Domańska, U.; Walczak, K. Ternary Liquid-Liquid Equilibria for Mixtures of \{Ionic Liquid + Thiophene or Benzothiophene + Heptane $\}$ at $\mathrm{T}=308.15$ K. J. Solution Chem. 2015, 44 (3-4), 382394.

(97) Rogošić, M.; Sander, A.; Kojić, V.; Vuković, J. P. Liquid-Liquid Equilibria in the Ternary and Multicomponent Systems Involving Hydrocarbons, Thiophene or Pyridine and Ionic Liquid (1-Benzyl-3Metylimidazolium Bis(Trifluorometylsulfonyl)Imide). Fluid Phase Equilib. 2016, 412, 39-50.

(98) Domańska, U.; Lukoshko, E. V.; Królikowski, M. Separation of Thiophene from Heptane with Ionic Liquids. J. Chem. Thermodyn. 2013, 61, 126-131.
(99) Regulatory Impact Analysis of the United States Environmental Protection Agency; EPA420-R00-026, United States Environmental Protection Agency.

(100) Kulkarni, P. S.; Afonso, C. A. M. Deep Desulfurization of Diesel Fuel Using Ionic Liquids: Current Status and Future Challenges. Green Chem. 2010, 12 (7), 1139-1149.

(101) Song, Z.; Zhang, C.; Qi, Z.; Zhou, T.; Sundmacher, K. Computer-Aided Design of Ionic Liquids as Solvents for Extractive Desulfurization. AIChE J. 2018, 64 (3), 1013-1025.

(102) Kalb, R. S.; Damm, M.; Verevkin, S. P. Carbonate Based Ionic Liquid Synthesis (CBILS®): Development of the Continuous Flow Method for Preparation of Ultra-Pure Ionic Liquids. React. Chem. Eng. 2017, 2 (4), 432-436.

(103) Kalb, R. S.; Stepurko, E. N.; Emel'yanenko, V. N.; Verevkin, S. P. Carbonate Based Ionic Liquid Synthesis (CBILS $®)$ ): Thermodynamic Analysis. Phys. Chem. Chem. Phys. 2016, 18 (46), 3190431913. 